\title{
The Reform and Optimal Allocation of Rural Financial Institutions from the Perspective of Multi-Task Principal-Agent Theory
}

\author{
Wang Jianfeng ${ }^{1, a^{*}}$, Chen $\mathrm{Wei}^{2}$, Mu Aiying ${ }^{3}$
}

\author{
${ }^{1}$ School of Economics and Management, Beijing Jiaotong University, Beijing, China \\ ${ }^{2}$ Hebei Provincial Department of Public Security, Shijiazhuang , China \\ ${ }^{3}$ Business School , Hebei University of Economics and Trade, Shijiazhuang , China \\ $a^{*}$ wang22jianfeng@163.com
}

\begin{abstract}
This paper study the reform and the best allocation of the rural financial institutions with a multi-task principalagent model. Our analysis shows that: (1) When the ability of the peasant to participate in the financial activities is weak, the radical commercialization reform of financial institutions will lead to lower social welfare. Otherwise the agricultural policy-oriented financial institutions will promote the rural financial market. (2) The original ability of the peasant to participate in the financial activities has an inverse relation to the best ratio of the agricultural policy-oriented financial institutions in the market. (3) If the government has another ways to improve the ability of the peasant to participate in the financial activities with lower cost, setting the agricultural policyoriented financial institutions is not a good way to improve the rural financial market.

Keywords: the reform of the rural financial institutions, the best ratio of the agricultural policy-oriented financial institutions, multi-task principal-agent model
\end{abstract}

\section{多任务委托代理视角下农村金融机构改革与最优配置}

\author{
王建峰 1 , a* 陈伟 ${ }^{2}$ 母爱英 3
}

\author{
北京交通大学经济管理学院, 北京, 中国 \\ 河北省公安厅，石家庄，中国 \\ 河北经贸大学商学院, 石家庄, 中国 \\ $a^{*}$ wang22jianfeng@163. com
}

\section{摘要}

本文在多任务委托代理框架下，研究了农村金融机构的改革和最优配置问题。本文的分析表明：（1） 当农民初始金融参与能力很低时，农村金融市场上需要一定比例的政策性金融机构，这时激进的商业 化改革会带来社会总福利的损失; 当农民参与金融活动的能力很高时，农村政策性金融机构的设立并 无必要。(2) 农民初始参与金融活动的能力与最优金融机构配置中的政策性金融机构比例呈反向关系。 （3）当政府无其他成本更低廉的途径来提高农民参与金融活动的能力时，设立农村政策性金融机构十 分必要; 反之则不必要。

关键词：农村金融机构改革；最优配置比例；多任务委托代理

\section{1. 引言与文献综述}

作为农村金融活动的主要载体, 农村金融机构的改 革进路对农村金融乃至整个农村经济的发展都有举足 轻重的影响。中国的农村金融机构主要有两种类型：其 一为单纯以盈利为目的商业性金融机构, 其二为同时要 
承担国家支农任务的政策性金融机构。从历史上看, 这 两种目标具有显著差异的金融机构的兴衰与变异构成 了中国农村金融机构改革的主线。中国农业银行自 1979 年恢复之后, 在很长一段时期内都在农村金融领域中处 于垄断地位。彼时的中国农业银行作为国务院的直属机 构, 不仅要开展资金信贷等常规金融业务, 而且要承担 国家交付的一系列政策性支农信贷任务，如国家农副产 品收购贷款、扶贫贷款、农业综合开发贷款等等。这种 状况直至 1993 后才有所改变。在国务院出台的《关于 金融体制改革的决定》的指导下, 中国农业银行转型为 商业银行, 国家指派的政策性业务亦转由从农行独立而 出的农村信用合作社以及新成立的中国农业发展银行 共同承担。与此同时, 伴随着中国农业银行从农村的撤 离, 农村信用社逐渐成为农村金融领域新的中坚力量。 近年来, 随着中国市场化改革的不断推进, 国家越来越 强调农村金融机构的市场主体地位以及自身的“造血” 功能。2012 年中央“一号文件”明确提出要发展多元性的 金融机构, 鼓励民间资本进入农村金融领域, 2015 年的 “一号文件”则进一步强调要支持各类商业银行创新“三 农”金融服务。目前中国农村金融机构的分布渐呈传统 与新型农村金融机构并存的多元格局。可以认为, 中国 农村金融机构改革是由国家主导型模式向市场主导型 模式渐变的过程。

与实际改革路径相匹配, 学界对农村金融机构的研 究亦多集中于寻找阻碍其发挥作用的各种约束条件以 及可能的金融技术和组织创新。洪正 (2011) [1]以监督 效率为切入点, 指出由国有银行组建的村镇银行和贷款 公司缺乏监督效率比较优势, 同时小额信贷对民营资本 监督效率提出了过高要求, 因此它们都难以在农村地区 普遍设立。而从农户生产经营中内生出来的资金互助社 由于可以实现相互监督和合同互联, 故其发展可显著改 善农村融资状况。鉴于此, 他指出进一步的改革需要逐 步从国家外生主导模式向民间内生成长模式转变, 充分 发挥民营资本和各类新型农村经济组织的作用。谭燕芝 等 (2014) [2]的研究发现县域经济发展水平与农村金融 机构多寡呈显著正相关关系, 并且这一结论同样适用于 商业类金融机构和农村类金融机构在县 (区)的布局设点。 他们的结论证明了区域经济水平对当地农村金融机构 发展的约束作用。徐忠、程恩江（2004）[3]认为农村金 融机构实行商业化改革后, 农村利率结构的扭曲是造成 农村金融机构亏损的主要约束, 而其后的农村金融市场 改革进一步加剧了农村利率结构的扭曲。董晓琳等 （2014）[4]通过对江苏省 48 个县 241 家金融机构的面 板数据研究, 认为市场逐步开放驱动了农村金融机构的 信贷技术创新行为, 并通过信贷技术创新降低了企业贷 款风险和交易成本, 进而提高了农村小微企业的信贷可 获得性, 缓解了农村小微企业的融资困境。王曙光 (2008) [5]以实地调研数据为基础, 考察了新型农村金融机构的 组建模式和资金配置效应，对新型农村金融机构的内部 治理结构和风险控制方面的创新机制进行了阐释, 并系 统的探讨了新型农村金融机构面临的制约因素及其应 对策略。曲小刚、罗剑朝（2013）[6]通过对新型农村金 融机构的研究, 认为它们可以有效地缓解农户和小企业
的信贷约束，但同时又有贷款对象偏离农户的趋势。

以上文献无疑对理解中国农村金融机构本身及其 发展进路多有洞见, 但它们亦有不足。具体而言, 在着 眼于如何让市场进一步发挥其资源配置作用的同时，现 有文献在强调金融机构组织创新的同事忽略了一个更 基本的问题，即中国二元经济体制下农村金融市场的弱 质性以及在该约束下国家力量参与其中的必然性。其实, 当处于相对贫困中的农民无力提供担保品时，单纯依靠 发展以盈利为目标的商业性金融机构来促进农村金融 发展可能并不现实。商业银行从农村的逃离, 农村信用 社和银行在发放贷款时对富有农户的偏爱（朱喜等, 2009)[7], 外资银行在农村的倾向性选址策略(周雯等, 2013) [8]，小额信贷的“目标上移”（刘西川等，2007） [9]都清楚的体现了这一点。这些现象的出现意味着我们 必须重新思考农村金融领域发展中的“国家一市场”关 系。虽也有学者的研究涉及到这一主题 (白晓燕、李锋,

2005; [10]孙建星, 2008[11]), 但他们都未能在理论上 完整刻画农村金融市场上两种目标不同的金融机构之 间的互动，因而不能全面的解释政策性金融机构的在农 村金融市场上的存在价值及其局限。

实际上，农村政策性金融机构所提供的金融服务本 质上具有公共品的性质: 它通过支持本不具备参与金融 活动能力农民的生产活动, 使其逐渐拥有参与金融的能 力。显然, 这种具有显著外部性的金融目标的实现同样 有利于单纯以利益最大化为驱动的金融机构的发展, 然 而后者却没有激励去完成它们。但同时，在提供政策性 金融服务的同时，目标的多元化以及国家权力的过多干 预又会损害金融机构的运营绩效，使其甚至不能自负盈 亏 (姚树洁等, 2004[12])。如此一来，政策性金融机构 的效率损失，与其因提供具有公共品性质的金融服务而 带来的社会收益就构成了追求社会福利最大化的国家 在配置最优农村金融机构格局中需要抉择的两难问题。 进而，在农村金融领域中，如何决定政策性金融机构的 比例, 以及该最优比例如何随着外部环境而变化就成了 一个政府在约束条件下的最优化问题。金融行业的特性, 以及农村金融机构的多目标特征，使该最优化问题十分 适宜在多任务委托代理模式下进行讨论, 这正是本文研 究的切入点。在本文中, 我们不仅会探究不同金融机构 之间复杂的互动关系, 也试图在一个统一的框架下理解 农村金融机构的发展路径以及中国农村的改革路径。

本文分析建立在多任务道德风险模型之上。

Holmstrom 和 Milgrom (1991) [13]作为先驱性文献, 最 早以连续型模型分析了多任务道德风险下的委托代理 模型，Laffont 和 Martimort（2002）[14]在一个离散模型 分析框架下得到了与 Holmstrom 和 Milgrom（1991）相 似的结论。在利用此框架进行中国问题研究的文献中, Bai 等（2000）[15]对中国国企改革路径和速度进行了 分析; 聂辉华 (2006) [16]考察了取消农业税对乡镇行 为的影响; 晏艳阳和金鹏（2013）[17]通过将委托人和 代理人公平偏好同时引入到多任务的委托代理模型中, 研究国企高管和政府主管部门均具公平偏好下的国企 高管最优薪酬机制。

本文剩余章节安排如下: 第二部分建立一个基于多 
$G=\int g_{i} d i+G_{0}$ 。

设每个金融机构 $i$ 的收益为 $L_{i}=\lambda_{i} y\left(s\left(s_{i}, G\right)\right.$, 其中 $\lambda_{i}$ 代表金融机构 $i$ 与金融机构 $a$ 全要素生产率的 比值，因此有 $\lambda_{a}=1$ 。由于金融机构 $b$ 的管理运营经 常会受到来自政府的干预, 设 $\lambda_{b}=\lambda$, 据上文所述, 有 $0<\lambda \leq 1$ 。

另外, 对函数y(·)我们有以下假设:

假设一: $\mathrm{y}(\cdot)$ 为凹函数且对 $S$ 和 $G$ 递增, 且有

假设在农村中金融机构 $i$ 分为两种类型。一种是单 纯以盈利为目的的商业性金融机构,一种是除盈利之外, 还要承担国家所交付的政策性支农任务的政策性金融 机构。我们称前者为金融机构 $a$, 后者为金融机构 $b$ 。 同时, 设 $r$ 为金融机构 $b$ 在农村金融机构中所占比例。 另外, 我们假设任何金融机构本身都是一个整体, 这也 就意味着我们并不区分金融机构的管理者与金融机构 本身, 金融机构内部的委托代理问题不在本文的分析范 围之内。

设两种金融机构的管理者将自身努力分配到两种 目标上。其一只能为本机构带来收益, 如一般性的资金 信贷业务项目。我们将两种金融机构的管理者置于该目 标的努力程度分别用 $\mathrm{s}_{a}$ 和 $\mathrm{s}_{b}$ 表示; 其二可增进农民整 体参与金融活动的能力, 如政策性的支农贷款。显然这 种目标的实现可以逐渐扩大农村金融市场, 并最终为包 括自身在内的所有金融机构带来收益, 因而它具有公共 品的性质。我们将两种金融机构的管理者置于该目标的 努力程度分别用 $g_{a}$ 和 $g_{b}$ 表示。

假设努力程度不可验证, 那么政府就不能通过基于 努力程度的合同来规制金融机构管理者的行为。但是, 因为政府对金融机构 $b$ 有较为深入的介入, 故而我们假 设政府可以通过观察来保证金融机构 $b$ 的管理者的努 力程度不低于一个常数值 $t$ 。因此我们有 $\mathrm{s}_{b}+g_{b} \geq t$ 。

设 $G_{0}$ 为不依赖于模型中的金融机构来增进的农民 参与金融活动的能力, 它与历史以及政府依靠设立农村 政策性金融机构之外的其他可提升农民参与金融能力 的政府活动有关。因这些变量外生于我们的模型, 故而 我们称其为农民的外生金融能力。设 $G_{0}>0$ 且 $G_{0}=G_{h}+G_{e}$ 。其中 $G_{h}$ 为农民的外生金融能力中从 之前历史上所传承下来的部分, $G_{e}$ 为政府通过其他途 径所增进的部分。

农村金融机构的努力 $g_{a}$ 和 $g_{b}$ 可以增加农民参与 金融的总能力 $G$ 。为简化分析, 我们设金融机构的每 单位 $g_{a}$ 或 $g_{b}$ 都可转化为一单位的农民参与金融能力。 因而在给出 $G_{0}$ 后, 农民参与金融的总能力为 $y_{s G}>0$ 。其中, $y(\cdot)$ 为凹函数且对 $s$ 和 $G$ 递增是对生 产函数的一般假定, $y_{s G}>0$ 刻画了 $s$ 和 $G$ 之间的互 补性。

假设二： $y_{s}(s, G)>1$ 。 $y_{s}(s, G)>1$ 意味着投 入 $s$ 的边际收益大于边际成本，该假设刻画了政府监督 的不完善。

假设三: $\lim _{G \rightarrow 0} y_{G}=\infty, \lim _{G \rightarrow \infty} y_{G}=0$ 。该假设刻画 了 $G$ 对收益的重要性。

假设四：金融机构的管理者是风险中性的。

假设五: 金融机构参与除农村金融以外的经济活动 收益为 0 。

假设六：设政府以追求社会福利最大化为目标, 因 而其决策函数为:

$\operatorname{Max} \pi=r\left[\lambda y\left(s_{b}, G\right)-s_{b}-g_{b}\right]+(1-r)\left[y\left(s_{b}, G\right)-s_{b}-g_{a}\right]$

\section{2. 参与约束 (IR) 与激励约束 $(I C)$}

\subsection{1，金融机构 $a$ :}

根据假设五, 对金融机构 $a$ 的管理者而言, 因为其 参与约束 $(I R)$ 必然能得到满足, 所以我们只需获得其激 励约束。

设 $P_{a}$ 为金融机构 $a$ 的利润函数, 因其目标为追求 自身利益最大化, 故其激励相容约束（IC1a）由下式得 到:

$$
\operatorname{MaxP}_{a}=y\left(s_{a}, G\right)-\left(s_{a}+g_{a}\right)
$$

对 (2) 式中的 $s_{a}$ 求一阶导使其等于 0 , 金融机构 $a$ 的激励相容约束 (IC1a) 为 $\frac{\partial y\left(s_{a}, G\right)}{\partial s_{a}}=1$ 。

同时, 注意到金融机构 $a$ 提供 $G$ 的边际成本为 
$\frac{\partial p_{a}}{\partial g_{a}}=1$, 而边际收益为 $\frac{\partial P_{a}}{\partial G} \cdot \frac{\partial G}{\partial g_{a}} \rightarrow 0$ 。因为有 $\frac{\partial P_{a}}{\partial g_{a}}>\frac{\partial P_{a}}{\partial G} \cdot \frac{\partial G}{\partial g_{a}}$, 所以金融机构 $a$ 的管理者不会提供任 何数目的 $G$, 即 (IC $2 \mathrm{a})$ 为 $g_{a}=0$ 。这也意味着社会中 的 $G$ 将由金融机构 $b$ 独自承担。因为我们假设了金融 机构的每单位努力 $g_{a}$ 或 $g_{b}$ 都可转化为一单位的农民 参与金融能力, 故有 $s_{b}=G$ 。

\subsection{2, 金融机构 $b$ :}

设作为受到国家控制的政策性金融机构, 金融机构 $b$ 的管理者获得固定工资 $w$ 且其利润函数为 $p_{b}$, 故其 激励相容约束（ICb）由下式决定:

$$
\begin{aligned}
& \operatorname{Max}_{b}=w-\left(s_{b}+g_{b}\right) \\
& \text { s.t. } s_{b}+g_{b} \geq t
\end{aligned}
$$

由于此时管理者获得固定工资, 因此他将其努力置 于争取更大利润, 抑或提高农民参与金融活动的能力, 于他并无差别。这也意味着此时的激励相容约束 ( $\mathrm{ICb})$ 总是成立。

同时，最优化的激励将令其拉紧激励约束，故而金 融机构 $b$ 的参与约束 $(\mathrm{IRb})$ 为: $s_{b}+g_{b}=t$

\section{3. 政府的最优规划结构}

设政府在最大化社会福利时按照以下方式进行决 策: 首先, 政府规定金融机构 $b$ 的比例 $r$; 然后, 政府 规定金融机构 $b$ 在提供 $G$ 中的努力 $g_{b}$ 。

在上文分析的基础上, 把将(IC2a)以及(IRb)代入目 标函数后, 此时的政府最优规划可重写为:

$$
\begin{aligned}
\operatorname{Max} \pi & =r[\lambda y(t-G, G)-t]+(1-r)\left[y\left(s_{a}, G\right)-s_{a}\right] \\
\text { s.t. } & \frac{\partial y\left(s_{a}, G\right)}{\partial s_{a}}=1 \\
G & =r g_{b}+G_{0} 。
\end{aligned}
$$

\section{3. 模型分析：最优农村金融机构配置}

下面我们将利用上述最优规划来讨论各种条件下 金融机构 $b$ 的最优比例 $r^{*}$ 及其变动, 并讨论其中的经济 含义。
3.1. 当政府决策为最优时, 有一阶条件为 $\frac{\partial \pi}{\partial r}=0$, 即: $\left[\lambda y(t-G, G)-t-y\left(s_{a}, G\right)+s\right]+\left[\lambda r y_{G}\left(t-g_{b}, G\right)+(1-r) G y_{G}\left(s_{a}, G\right)\right]=0$ 由于 $\lambda y(t-G, G)-t$ 为金融机构 $b$ 最优收益, $y(s, G)-s_{a}$ 为金融机构 $a$ 的最优收益, 显然有:

$$
\lambda y(t-G, G)-t-y(s, G)+s_{a}<0
$$

要达到最优, 这时必须有

$\lambda r y_{G}(t-G, G) G+(1-\mathrm{r}) \mathrm{Gy}_{\mathrm{G}}\left(\mathrm{s}_{\mathrm{a}}, \mathrm{G}\right)>0$ 。根 据假设三, 有当 $G_{0} \rightarrow \infty$ 时, 有 $y_{G} \rightarrow 0$ 。因此存在 $G_{1}$, 当 $G_{0}>G_{1}$ 时, 始终有:

$\lambda r y_{G}(t-G, G) G+(1-\mathrm{r}) \mathrm{Gy}_{\mathrm{G}}\left(\mathrm{s}_{\mathrm{a}}, \mathrm{G}\right) \rightarrow 0$, 从 而 (5) 式等号左边部分小于 0 。这也就意味着此时的最 优点为角点解 $r^{*}=0$, 即市场上金融机构 $b$ 所占比例 为零。

命题 1：当农民的外生性金融能力充分强时，农村 金融市场上并不需要政策性金融机构。

命题 1 符合我们的直觉。从本质上而言, 设立政策 性金融机构的目的是为了提升农民原本疲弱的金融参 与能力, 但是, 实现该目的却是以牺牲市场效率为代价 的。因此如果农民的外生金融能力已足够强，或者更具 体来说, 农民有足够强的经济能力提供抵押品, 那么再 发展政策性金融机构将得不偿失。这也解释了为什么在 相对富裕的城市中不需要农发行等立足于培养个体金 融参与能力的政策性金融机构。同时, 命题 1 也意味着 农村政策性金融机构本质上只是一种过渡性的组织: 当 农民足够富裕从而其金融参与能力足够强时，农村政策 性金融机构的存在就不再具有经济上的合理性。

3.2. 当 $G_{0}$ 充分小, 根据假设三, 有 $\lim _{G \rightarrow 0} y_{G}=\infty$, 故当 $G_{0} \rightarrow 0$ 时, 有: $\left[\lambda r y_{G}\left(t-g_{b}, G\right)+(1-\mathrm{r}) \mathrm{Gy}_{\mathrm{G}}\left(\mathrm{s}_{\mathrm{a}}, G\right)\right] \rightarrow \infty$ 。 因为: $\frac{\partial \pi}{\partial g}=-r \lambda y_{s_{a}}\left(t-g_{b}, G\right)+r \lambda y_{G}\left(t-g_{b}, G\right)+(1-r) y_{G}$, 且 $\lim _{G \rightarrow 0} y_{G}=\infty$, 故当 $G_{0} \rightarrow 0$ 时, $\frac{\partial \pi}{\partial g_{b}}>0$ 。根据命 题 1 , 这也同时意味着当 $r \rightarrow 0$ 时, $\frac{\partial \pi}{\partial g_{b}}>0$, 即这 时最优的 $g_{b}{ }^{*}>0$ 。因为 
外生金融能力, 则导致自我“造血”式的小额信贷模式在 $\frac{\partial \pi}{\partial r}=\left[\lambda y\left(t-g_{b}, G\right)-t-y\left(s_{a}, G\right)+s_{a}\right]+\left[\lambda r y_{G}(t-G, G) G+(1-r) G y_{G}\left(s_{a}, G\right)\right]$ 故有 $\frac{\partial \pi}{\partial r}>0$ 。显然, 此时最优的比例 $r^{*}>0$ 。

命题 2: 农民的外生金融能力非常弱时，农村金融 市场上需要有一定比例的政策性金融机构。

2015 年的中央一号文件提出在对农村金融的深化 改革过程中, 要坚持“推动金融资源持续向“三农”倾斜, 确保涉农贷款比例不降低、农业信贷总量继续增加”, 同时要求中国农业发展银行首先“要强化政策性功能定 位, 同时加大对贫困地区公路、水利等农业农村基础设 施建设的贷款力度”，其次“要审慎发展自营性业务”。 命题 2 为这些政策提供了理论上的合理性证明。在弱质 性的农村金融市场, 政策性金融机构所具备的提高农民 参与金融能力的功能十分重要, 它不仅提高了农民参与 金融的能力, 而且最终将提高整个农村金融市场的效率 水平。命题 2 也同时意味着过于强调农村金融机构自我 “造血”功能的商业化改革思路是有待商榷的。不同于本 身就具备较高金融参与能力的市民, 农民较低的资产总 额导致其无力为其信贷行为提供抵押品。这时, 如果仅 仅依靠以盈利为目的的商业性金融机构, 或者过于激进 的推行农业发展银行等政策性金融机构的商业化改革, 则农村金融市场必然会进一步萎缩。

结合命题 1 和命题 2 , 又可为我们理解小额信贷在 中国农村的发展状况提供一种思路。以孟加拉国乡村银 行为代表的小额信贷机构, 其贷款技术和保障还款机制 等金融技术本质上都是中性的，因而也是易于移植的。 但是该小额信贷却在不同地区展现出的截然不同的绩 效。如在我国乡村, 虽有政府支持以及来自学界的实践 努力, 却未能在发展上呈如在孟加拉国一般的燎原之态, 甚至小额信贷机构本身的扶贫性质也在一定程度上被 弱化 (刘西川等, 2007[18])。针对这一问题的解释, 学 界的研究多集中于对融资环境、贷款途径及对象和机构 管理水平等方面的讨论（赵敏, 2007[19]）。而以命题 1 和 2 的角度来看, 我们认为正是不同国家之间迥异的农 民外生金融能力 $G_{0}$ 导致了这种绩效差异。具体而言, 孟加拉国的小额信贷机构之所以在扶贫的同时能够盈 利, 原因在于当地的贫困农民在获得贷款后可以马上通 过例如经营小生意等方式迅速增加自己的收入, 而这种 对未来收入提升的强大预期进而可增进小额贷款机构 对借款者还款能力信心。这也就意味着孟加拉国的农民 具有较高的外生金融能力 $G_{0}$ 。但在产能过剩、竞争激 烈的中国市场中, 农民即使拿到了小额贷款也很难通过 简单的生产经营活动顺利的增加收入。而缺乏了借贷双 方对未来还款能力的预期, 中国农民的外生金融能力 $G_{0}$ 自然就低的多。这种不同外生金融能力 $G_{0}$ 进而导致 拥有类似金融技术的小额信贷机构发展绩效的分岔: 孟 加拉国农民具有较高的外生金融能力使格莱珢银行等 小额贷款机构可以在扶持农民的同时自负盈亏，所以孟 加拉国的农村不需政策性金融机构; 而中国农民较低的 我国农村的发展必然会有一定程度的水土不服, 因而带 有支农性质的金融信贷活动须由政策性金融机构承担。

3.3. 为了进一步看到 $G_{0}$ 如何影响 $r^{*}$ 的选择, 我们求得:

$$
\frac{\partial^{2} \pi}{\partial r \partial G_{0}}=\left[\lambda y_{g}\left(t-g_{b}, G\right)-y_{g}\left(s_{a}, G\right)\right]+\left[\lambda r y_{G G}\left(t-g_{b}, G\right) G+(1-r) G y_{G G}\left(s_{a}, G\right)\right]
$$

因为函数 $\mathrm{y}(\cdot)$ 为凹函数, 因此 $\left[\lambda r y_{G G}\left(t-g_{b}, G\right) G+(1-r) G y_{G G}\left(s_{a}, G\right)\right]<0$ 。

又因为 $y_{s G}>0$, 故而,

$$
\begin{aligned}
& \lambda y_{g}\left(t-g_{b}, G\right)-y_{g}\left(s_{a}, G\right)<0, \\
& \quad \text { 进而有 } \frac{\partial^{2} \pi}{\partial r \partial G_{0}}<0 \text { 。这也就意味着 } \frac{\partial r}{\partial G_{0}}<0 。
\end{aligned}
$$

命题 3: 随着农民外生金融能力的增大，农村金融 市场上的政策性金融机构所占比例会减小。

命题 3 证明了中国农村金融机构商业化改革在方向 上的合理性。根据上述模型的逻辑, 政策性金融机构会 带来更高的农民参与金融能力, 而这种能力的提高又会 反过来放大政策性金融机构与盈利性金融机构之间的 效率差别，进而使前者在金融机构的最优配置中比例降 低。

但命题 3 同时也意味着商业化改革的速度必须适宜, 要与农民参与金融的实际能力相适应。当农民参与金融 的能力过低时, 激进的商业化改革只会破坏本已脆弱的 农村金融市场, 得到正好相悖于改革本意的结果; 而只 有在农民参与金融的能力获得长足的提高后, 通过有效 率的盈利性金融机构对政策性金融机构的逐渐替代, 近 年来从政府到学界一直强调由市场力量主导的新的农 村金融生态才能形成。简言之, 太快或太慢的商业化改 革都会削弱社会总福利: 前者会导致农村金融市场的萎 缩, 后者会使农村金融市场的发展掣肘于政策性金融机 构的低效。

3.4. 因为 $G_{0}=G_{h}+G_{e}$, 而 $G_{e}$ 的建立需要政府花费一 定成本, 我们设该成本为 $C \varphi\left(G_{e}\right)$, 则政府的最优规 划可以进一步地写为:

$$
\begin{aligned}
& \operatorname{Max} \pi=r[\lambda y(t-g, G)-t]+(1-r)\left[y\left(s_{a}, G\right)\right]-C \varphi\left(G_{e}\right) \\
& \text { s.t. } G=r g+G_{h}+G_{e} \\
& \frac{\partial y\left(s_{a}, G\right)}{\partial s_{a}}=1 \\
& s_{b}+g_{b}=t
\end{aligned}
$$


村金融市场上需要一定比例的政策性金融机构; 反之,

我们定义 $\omega\left(G_{e}\right)=\pi\left(G_{e}\right)-C \varphi\left(G_{e}\right)$ 。

根 据 包 络 定理, 我们有 $\pi^{\prime}\left(G_{e}\right)=r \lambda y_{G}(t-g, G)+(1-r) y_{G}\left(s_{a}, G\right)$.

根据命题一, 我们可知存在 $G^{*}$, 当 $G_{e}>G^{*}$ 时, 有 $r^{*}=0$ 。

令 $\beta$ 为当 $G_{e}<G^{*}$ 时, $\pi^{\prime}\left(G_{e}\right)$ 的最小值。

这时, 如果 $C$ 足够小, 则当 $G_{e} \leq G^{*}$, 有 $C \varphi^{\prime}\left(G^{*}\right)<\beta, \omega^{\prime}\left(G_{e}\right)>0$ 。这意味着政府此时会 选择 $G_{e}>G^{*}$, 进而在这样的最优选择下, 有 $r^{*}=0$ 。

令 $r$ 为 $G_{e}<G^{*}$ 时的最大值。

同样, 根据命题 2 , 我们可知存在 $G^{* * *}$, 使得当 $G_{e}<G^{* * *}$ 时, 有 $r^{*}>0$ 。

如果 $C$ 足够大, 则有当 $G_{e} \geq G^{* * *}$ 时, 有 $C \varphi^{\prime}\left(G^{* *}\right)>r, \omega^{\prime}\left(G_{e}\right)<0$ 。这意味着此时政府的 最优选择 $G_{e}$ 将小于 $G^{* * *}$, 进而在这样的最优选择之下, 有 $r^{*}>0$ 。

命题 4: 当政府利用其他渠道提高农民金融能力的 成本足够小时, 最优 $r^{*}=0$; 当政府利用其他渠道提高 农民金融能力的成本足够大时, 最优 $r^{*}>0$ 。

从本质上来讲, 农村金融市场之所以更难发展的主 要原因在于农民手中可供抵押的资产品不足, 从而无法 为其金融活动提供抵押品。而根据我们的模型, 农村政 策性金融机构的存在意义恰恰在于其普惠性的金融活 动可以增进农民参与金融的能力。但是, 就提高农民金 融能力而言, 设立和扶持政策性金融机构并不是唯一的 途径。除此之外, 如土地确权、户籍制度改革、直接的 财政补贴等政府行为亦可同样通过增加农民的财富达 到此一目标。但无论是哪种途径, 也都会产生一定的成 本。因此一个以社会福利最大化为目标的政府必然要有 意的选择更低成本的途径。这时, 如果通过设立政策性 金融组织来提高农民的金融参与能力的成本更低, 则农 村金融市场中的政策性金融机构的比例应为正; 如果有 其他成本更低的途径可以实现同样的目标, 则政策性金 融机构的设立就不再必要。实际上, 命题 4 促使我们将 视野置于金融机构之外, 以农村经济整体发展的视角来 看待农村金融机构的改革。

\section{4. 结论与拓展性解释}

本文在多任务道德风险的框架下, 以正式的理论模 型分析了农村金融机构的改革和最优配置问题。在明确 的区分了单纯以盈利为目的的农村商业性金融机构和 还要承担支农任务的农村政策性金融机构之后, 本文的 分析表明: 1、如果农民初始参与金融能力很弱, 则农
则农村政策性金融机构的设立只能带来社会总福利的 损失。2、农民初始参与金融能力与最优机构配置中政 策性金融机构的比例呈反向关系。3、当政府无成本相 对更低廉的途径提高农民参与金融活动的能力时，农村 政策性金融机构的设立十分必要; 反之则不必要。

与以往研究着重强调市场作用的不同, 我们刻画了 非市场力量在促进农村金融发展中的作用。经过规范的 理论分析, 我们认为, 在市场主体参与能力不强的情况 下，过激的商业化改革只能带来适得其反的后果。根本 原因在于，农村金融的发展有赖于市场主体基于其财富 能力的较高水平的信用水平, 而这种信用水平并不能单 纯依靠市场的发展来获得。但需要指出的是, 这并非否 定农村金融机构商业化改革的方向，而是说在改革的路 径中, 改革速度必须与农民的金融参与能力相适应。否 则, 如模型的结果所示, 过快的商业化改革只会带来农 村金融市场的进一步萎缩, 从而损害整个农村社会的总 福利; 而过慢的商业化改革则会使农村发展掣肘于金融 机构的低效率。另外, 我们的研究表明, 对农村金融机 构改革的研究不能将视野仅局限在金融机构内部。不同 经济部门之间的密切联系, 使农村经济中其他领域的发 展同样会改变不同金融机构的社会相对价值, 从而影响 到农村金融机构的改革和最优配置。

实际上, 对本文结论的拓展性解释还可以帮助我们 理解整个农村经济改革的最优路径。根据本文模型所展 现的逻辑, 如果某些部门的产出对社会整体福利影响巨 大, 则即使是低效率的, 国家通过输血的方式予以扶持 依然可能有利于社会整体福利的提高。对农村经济的诸 多领域而言, 市场主体参与能力不强是其显著特征。因 此根据本文的逻辑, 这也就意味着一定时期内国家力量 对某些农村经济部门的深度参与十分必要。此时过激的 市场化改革反而只会导致市场的进一步萎缩。但是这并 不意味着我们否认市场化改革路径。同样与我们模型的 逻辑一致, 诸多领域中农村改革中的国家力量对市场的 干预在时间维度上只能是一种过渡性的举措。当市场逐 渐成熟、农民市场参与能力得到足够提升之后, 农村的 发展依然要依靠市场的力量。

\section{项目基金}

本文为河北省社会科学基金项目（HB19YJ025）的 阶段性成果之一。

\section{REFERENCES}

[1] Hong Zheng. Is the reform of new rural financial institutions feasible? - Analysis from the perspective of supervision efficiency [J]. Economic research, 2011 (2): 44-58

[2] Tan Yanzhi, Chen Bin, Tian longpeng. What factors lead to the problem of Rural Financial Exclusion to what 
extent -- An Empirical Analysis Based on the data of 667 counties (districts) in the central six provinces in 2010 [J]. Economic review, 2014 (1): 25-37

[3] Xu Zhong, Cheng Enjiang. Interest rate policy, behavior of rural financial institutions and rural credit shortage [J]. Financial research, 2014 (12): 34-44

[4] Dong Xiaolin, Zhang Xiaoyan, Yang Xiaoli. Scale of financial institutions, loan technology and credit availability of rural small and micro enterprises [J]. Agricultural technology and economy, 2014 (8): 100-107

[5] Wang Shuguang. Operation performance and mechanism innovation of new rural financial institutions [J]. Journal of the Party School of the CPC Central Committee, 2008 (2): 60-65

[6] Qu Xiaogang, Luo Jianchao. Current situation, constraints and Countermeasures of sustainable development of new rural financial institutions [J]. Journal of China Agricultural University (SOCIAL SCIENCE EDITION), 2013 (2): 137-146

[7] Zhu Xi, Ma Xiaoqing, Shi Qinghua. Credit, wealth and rural credit rationing: supply behavior of different rural financial institutions in underdeveloped areas [J]. Financial research, 2009 (8): 4-14

[8] Zhou Wen, Wen Liqin, Li Chaoyang. A study on the location choice of foreign-funded new rural financial institutions in China: An Empirical Study Based on logit model [J]. Economic issues, 2013 (7): 51-55

[9] Liu Xichuan, Huang Zuhui, Cheng Enjiang. The goal of microcredit moving up: phenomenon description and theoretical explanation: a survey of farmers based on three provinces (districts) microcredit project areas [J]. China rural economy, 2007 (8): 23-34

[10] Bai Xiaoyan, Li Feng. An Empirical Study on the contribution of agricultural policy finance to agricultural economic growth in China [J]. Agricultural economic issues, 2005 (7): 21-24

[11] Sun Jianxing. Co integration analysis of credit input and grain production of agricultural policy banks: a case study of Henan Province [J]. Financial theory and practice, 2008 (11): 66-68

[12] Yao Shujie, Feng Genfu, Jiang Chunxia. Empirical analysis of the efficiency of China's banking industry [J]. Economic research, 2004 (8): 4-15.

[13] Holmstrom, B and Milgrom, P. Multitask Principal-agent Analyses: Incentive Contracts, Asset Ownership, and Job Design[J] . Journal of Law, Economics \& Organization, 1991(7): 24-52.

[14] Laffont, J.J.andMartimort, D. The Theory of Incentives: the Principal-Agent Model[M], Princeton: Princeton University Press, 2009.

[15] Bai,C E, Li,D D , Tao,Z, et al. A Multitask Theory of State Enterprise Reform[J]. Journal of Comparative Economics, 2000(4): 716-738.

[16] Nie Huihua. The impact of abolishing agricultural tax on the behavior of township government: a multi task principal-agent model [J]. World economy, 2006 (8): 71-78

[17] Yan Yanyang, Jin Peng. Multitasking goal under fair preference and executive compensation incentive in state-owned enterprises [J]. China management science, 2014 (7): 82-93

[18] Liu Xichuan, Huang Zuhui, Cheng Enjiang. The goal of microcredit moving up: phenomenon description and theoretical explanation: a survey of farmers based on three provinces (districts) microcredit project areas [J]. China rural economy, 2007 (8): 23-34

[19] Zhao min. Bangladesh Rural Bank model and the development of rural microfinance in China [J]. Shandong Social Sciences, 2007 (8): 62-64 